\title{
Interactive comment on "A compact Incoherent Broadband Cavity Enhanced Absorption Spectrometer (IBBCEAS) for trace detection of nitrogen oxides, iodine oxide and glyoxal at sub-ppb levels for field application" by Albane Barbero et al.
}

Albane Barbero et al.

albane.barbero@univ-grenoble-alpes.fr

Received and published: 9 July 2020

Dear Editors, We express our gratitude for the time and effort dedicated to the reviewing of our submitted manuscript. We worked diligently to address all the concerns raised by the referees and we thank the reviewers for the pertinent remarks that allowed to improve the manuscript. Attached we provide our detailed response to their comments. We hope that the applied revisions are to the satisfaction of the editors. 
Kind regards, Albane Barbero, Camille Blouzon, Joelíl Savarino, Nicolas Caillon, Aurel̀Ąlien Dommergue, and Roberto Grilli

Please also note the supplement to this comment:

https://www.atmos-meas-tech-discuss.net/amt-2020-104/amt-2020-104-AC1-

supplement.pdf

Interactive

comment

Interactive comment on Atmos. Meas. Tech. Discuss., doi:10.5194/amt-2020-104, 2020. 